\title{
التقنيات و الوسائل في تدريس القراءة \\ فى المدرسة الإبتدائية

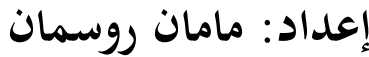

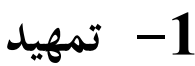

اللغة وسيلة من وسائل الاتصال بين الناس. و لكل لغة عناصر خاصة و من عناصر اللغة هي الأصوات و المفردات و التراكيب و الدلالة. و لكل لغة مهارات و هي الاستماع و الكلام و القراءة و الكتابة. فالقراءة هي مهارة لا يتقنها متعلم لغة ما إلا بكثرة التدريبات في القراءة و بعد اتقانه في القواعد و الدلالة. و في عملية تدريس المهارات اللغوية و خاصة في تدريس مهارة القراءة في المدرسة الإبتدائية يحتاج المدرس إلى التقنيات و الوسائل التى تساعده في تسهيل عملية تدريس القراءة و في تنمية رغبة الطلبة في القراءة و لترقية مهارقم فيها. فلا بد لكل مدرس لغة ما أن يعلم التقنيات و الوسائل المناسبة و الفعالة لتدريس القراءة. لذلك نورد في هذا المقالة بعض التقنيات و الوسائل و الاختبار و المصادر في تدريس القراءة في المدرسة الإبتدائية.

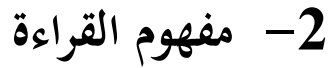

ما زال مفهوم القراءة في السابق كما اتفقه علماء التربية يسيرا و بسيطا بداية. و هو استيعاب المتعلم مهارة للوقوف على الكلمات و الحروف و كيفية تعبيرها إلى أن يكون هدف المدرس في هذا الصدد على حد تمكين المتعلم من إخراج الحروف من مخارجها الصحيحة و نطق الكلمات بصوت مسموع بعد أن أدركها بصريا دون الاهتمام بالمدلول الذي تؤديه هذه الكلمات و فهم معناها. و كانت طريقة 
التعليم التى واكبت هذا المفهوم الطريقة التركيبية، لأن الأساس الذى قامت عليه الطريقة هو التعرف على الكلمات و النطق بها. تم تطور هذا المفهوم نتيجة للبحوث التربوية التى أجراها كثير من علماء التربية التى هون أثبتت أن القراءة ليست عملية ميكانيكية تقوم على بجرد التعرف على الحروف و و الكلمات و النطق بها. بل أها عملية معقدة تماثل جميع العمليات التى يقوم بها الإنسان في التعلم فهي تستلزم الفهم و الربط و الاستنتاج. و نتيجة لذلك ازداد الاهتمام بالفهم في القراءة كعنصر ثان من عناصر العملية. في الحقيقة، كانت القراءة نشاطا عاما يقوم به الإنسان كل يوم، كقراءة القرآن و قراءة الجريدة و قراءة المحلة و الرسالة و هلم جرا. كيفما متى المقروء باللغة الأجنبية

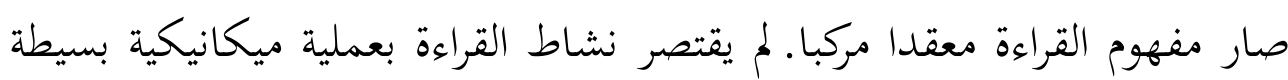

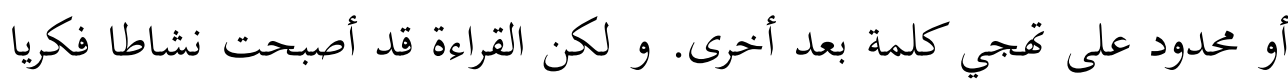
يستلزم تدخل جماع شخصية الفرد. و من ثم استنبط محمود كامل الناقة و رشدى

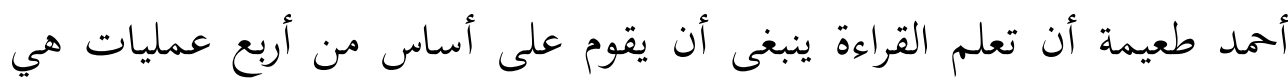
التعرف و الفهم و النقد و حل المشكلات.

في المفهمو الآخر بين حسن شحاتة أن نشاط القراءة عملية عقلية انفعالية دافعية تشمل تفسير الرموز و الرسوم التى يتلقاها القارئ عن طريق عينه، و فهم المعانى،

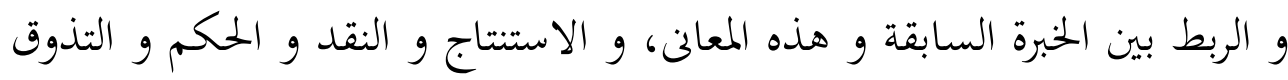
وحل المشكلات. اعتمادا على مفهمو القراءة الواسع، نصح محمد بن إبراهيم الخطيب المدرسين على

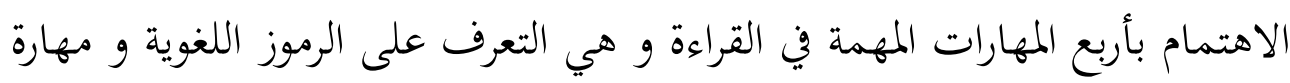
الفهم و السرعة في القراءة و الطلاقة في القراءة. 
إن للقراءة فن المدرسة الإبتدائية أهدافا متعددة و متباينة، الأمر الذي يؤثر في طبيعة عملية القراءة ذاها. و من بين هذه الأهداف ما يلي:

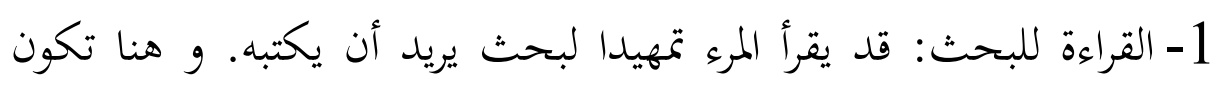

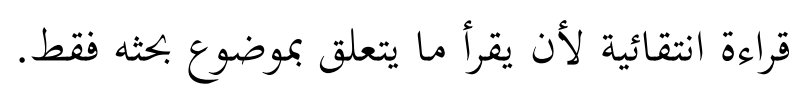

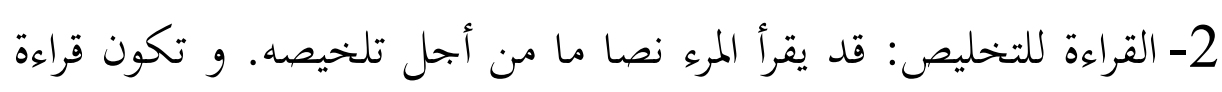

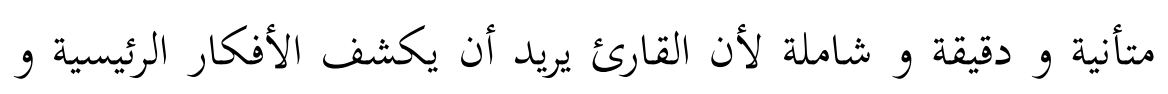
يستبعد التفاصيل غير المهمة. 3- القراءة للإعلام: قد يقرأ المرء ليسمع الآخرين مثلما يفعل المذيع في المدياع

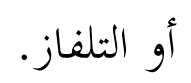

4- القراءة للاختبار: قد يقرأ المرء استعدادا لاختبار ما، و تكون قراءة دقيقة متأنية. 5- القراءة للمتعة: قد يقرأ المرء من أجل المتعة و تمضية الوقت.

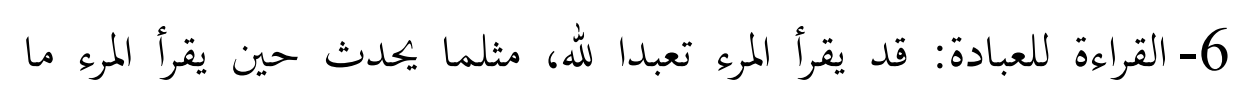

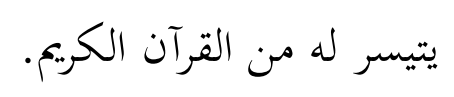

\section{ب- المستويات اللغوية التي تستحق في مهارة القراءة}

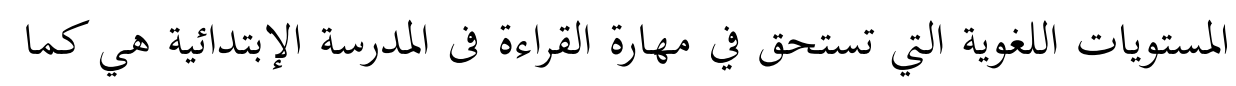
يلي: - ne

1- نطق كل حروف عربي نطقا سليما و صحيحا مناسبا بمخارج الحروف الئل

$$
\text { العربي بدأ من الألف (ا) حتى الياء (ي). }
$$

2- قراءة حروف عربي منظمة في كلمة واحدة قراءة صحيحة بنسبة علم الماء

$$
\text { الصرف. }
$$

3- قراءة كلمة عربية منظمة في جملة واحدة قراءة صحيحة بنسبة علم المرف

$$
\text { الصرف و النحو. }
$$


4- فهم الموقع كل الكلمة في الجملة فهما جيدا حسب قواعد اللغة العربية.

$$
\text { 5- فهم محتويات المقروء. }
$$

6- إيجاد ذوق العربي حتى يستطيع قراءة النصوص بتنغيم و نبر صحيح و سليم.

\section{ج- أهداف تعليم مهارة القراءة}

أما أهداف تعليم مهارة القراءة فن المدرسة الإبتدائية هي كما تلي:

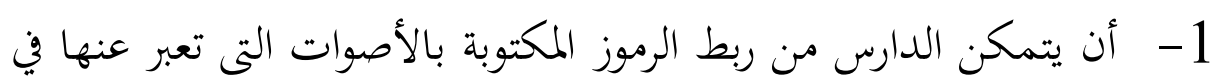

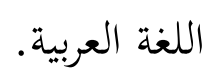

$$
\text { 2- أن يتمكن من قراءة النص قراءة جهرية بنطق صحيح. }
$$

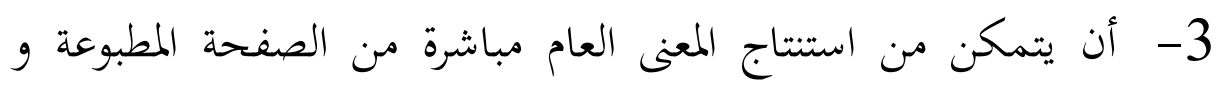

$$
\text { إدراك تغير المعنى بتغير التراكيب. }
$$

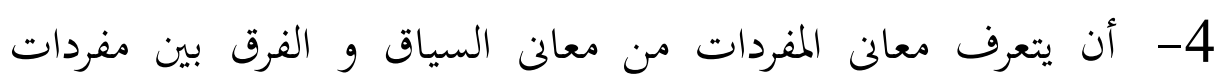

$$
\text { الحلديث و مفردات الكتابة. }
$$

5- أن يفهم معانى الجمل في المفردات و إدراك علاقات المعنى التى تربط

$$
\text { بينها. }
$$

6- أن يقرأ بفهم و انطلاق دون أن يعوق ذلك قواعد اللغة و صرفها.

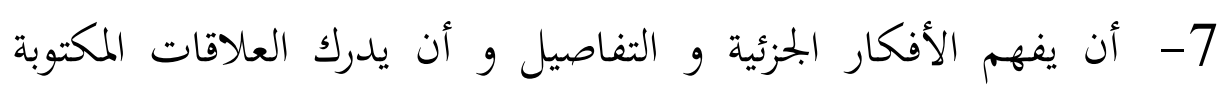

$$
\text { للفكرة الرئيسية. }
$$

$$
\text { 8- أن يتعرف علامات الترقيم و وظيفة كل منها. }
$$

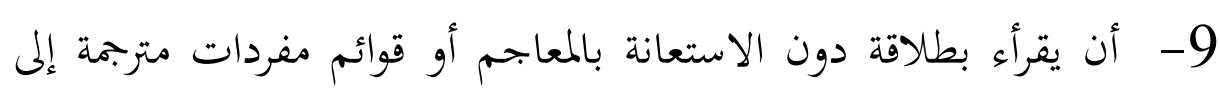

اللغتين.

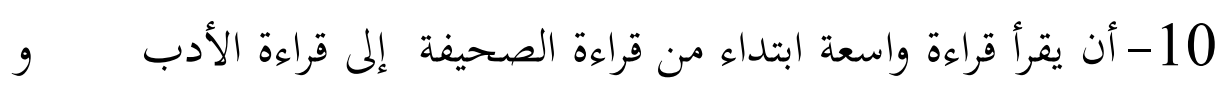

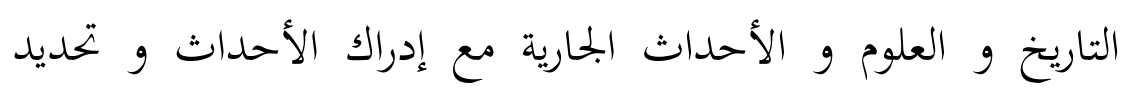


النتائج و تحليل المعنى و نقدها و ربط القراءة الواسعة بالثقافة العربية

$$
\text { الإسلامية. }
$$

ولو نظرنا بالدقة إلى أهداف تعليم مهارة القراءة السابقة، يمكننا الاستباط منها أن تعليم مهارة القراءة عملية نمو متدرجة حتى أن يبلغ إلى مهارة

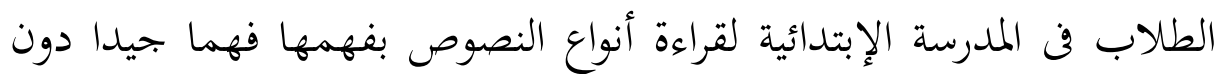

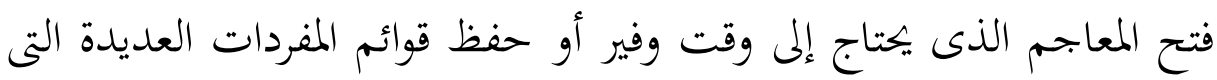
قد تكون عبئا على الطلاب و يؤدى إلى تأثير سلبي بظهور الشأمة و الملل للقراءة.

\section{د- مستويات تعليم القراءة}

يميز الخبراء بين ثلاثة مستويات لتعليم القراءة تتمشى مع مستويات تعليم العربية أي المستوى المبتدئ و المتوسط و المتقدم.

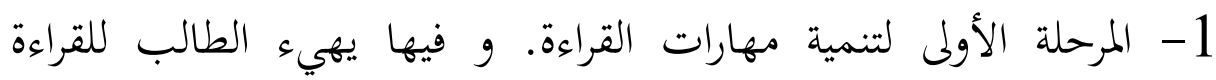

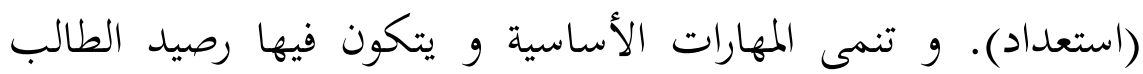
لغويا.

2- المرحلة المتوسطة لتنمية مهارات القراءة. و فيها يتم التركيزعلى إثراء مفردات الطالب و تنمية رصيده في التراكيب اللغوية و تتسع أمامه موضوعات القراءة إلى حد ما. 3- المرحلة المتقدمة: الاستقلال في القراءة. و في هذه يتدرب الطالب على تنمية مفرداته ذاتيا. و يتعلم كيف يستخدم القواميس و يبدأ أولى الى خطوات الاستقلال في القراءة. 
ينبغى عند اختيار مواد القراءة بالعربية في تعليم العربية لغير الناطقين بها مراعاة

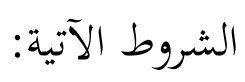

1- أن تكون باللغة العربية الفصحى. أي لا تحتوى على كلمات من لهجة

$$
\text { خاصة أو عاميةعربية معينة. }
$$

2- أن تلائم اهتمامات الدارسين و ميولمم و أعمارهم. فلا نقدم للكبار نصا معينه

يمكن أن يقدم للأطفال فيشعرون بالمهانة و استصغار تفكيرهم.

3- أن يحتوى النص على مفردات مرتبطة باهتمامات الطلاب و أعمالهم

$$
\text { التى يريدون تعلم العربية من أجلها. }
$$

4- أن يبنى لدى الطلاب قيمة أخلاقية معينة أو يعرفهم بنمط ثقافي إسلامي الميا. معين دون أن يتعارض مع قيم الطلاب أو يمتهن ثقافتهم. اللهم إلا في الحالات التى تتعارض فيها هذه القيم مع الثقافة الإسلامية.

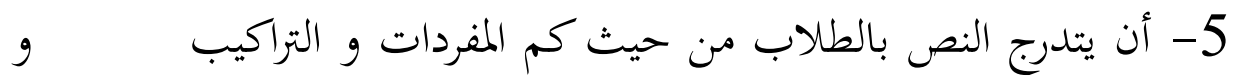

نوعها. فيبدأ بما درسوه شفهيا. و ما يستطيعون استعماله في مواقف بـف

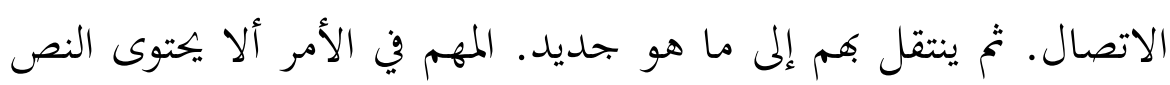

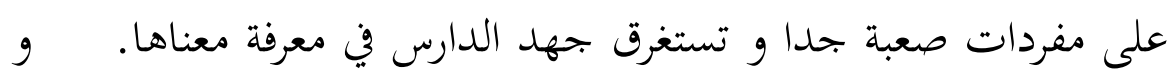
تضيع عليه لذة تحصيل المعرفة من الصفحة المطبوعة.

\section{3- التقنيات في تدريس مهارة القراءة}

تتضمن في تقنيات التدريس المدخل و الطريقة و كذلك الأسلوب. و لقد ظهرت

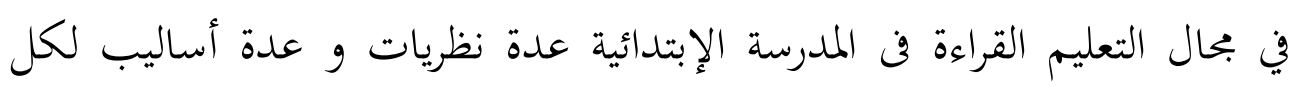

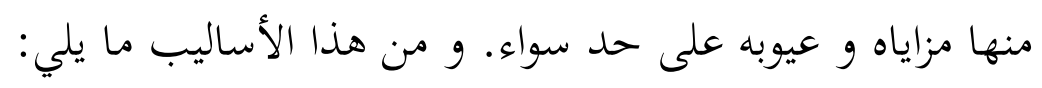

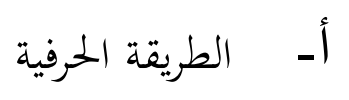

يبدأ المعلم هنا بتعليم حروف الهجاء واحدا بعد الآخر. فيتعلم المتعلم ألف، باء، تاء... إلى آخره. و يتعلم الطالب قراءة الحرف إذا رآه مكتوبا، 
كما يتعلم كتابة هذه الحروف. و بعد ذلك، يتعلم الطالب قراءة المقاطع

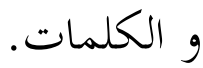

$$
\text { ب- ب- الطريقة الصوتية }
$$

تشبه الطريقة الصوتية الطريقة الحرفية من حيث الانتقال من الحروف إلى

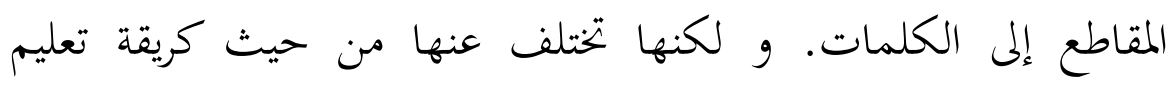
الحرف. فالحرف في الطريقة الحرفية يعطي اسما؛ فالحرف ص مثلا يعلم على الى الى

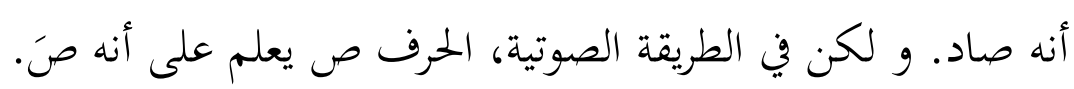
ج- الطريقة المقطعية

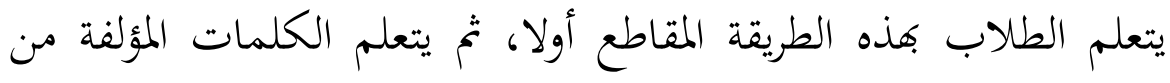
مقاطع. و لتعليم المقاطع، لا بد من تعليم حروف المد أولا. فيتعلم

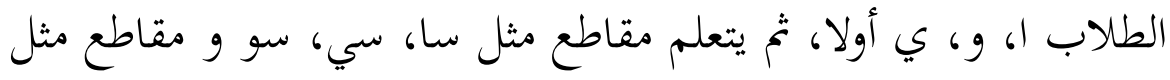
را، ري، رو، و كلمات مكونة من مقاطع تعلمها مثل سارا، سيري،

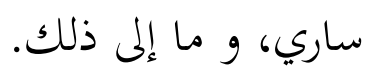
د- مريقة الكلمة

طريقة الكلمة احدى الطرق الكلية، لأن المتعلم يتعلم الكلمة أولا ثم يتعلم

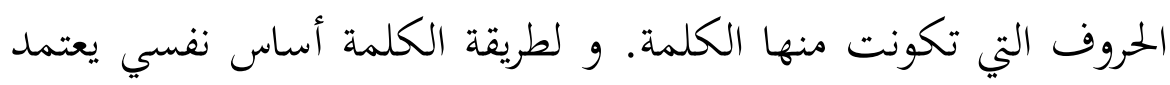

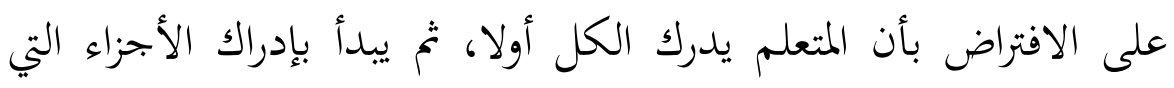

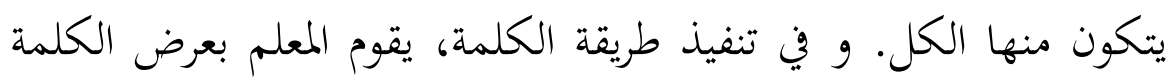

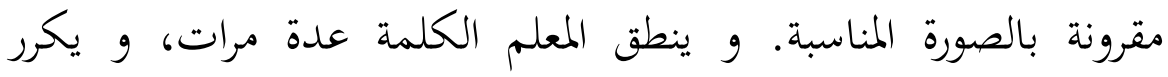
الطلاب من بعده. ثم يعرض المعلم الكلمة من غير صورة ليطلب من

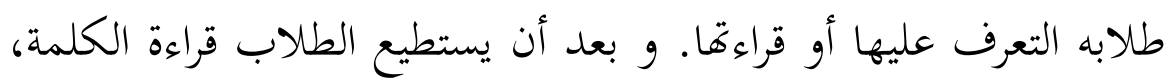
يبدأ المعلم في تحليلها إلى الحروف التي تتكون منها. 
- - مريقة الجملة

يتم تعليم القراءة بطريقة الجملة بأن يعرض جملة قصيرة على البطاقة أو

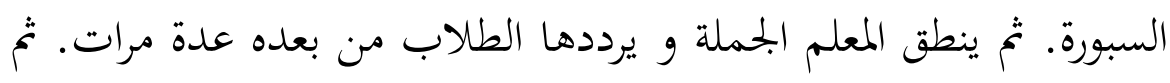
يعرض المعلم جملة تزيد عن الجملة الأولى كلمة واحدة و ينطقها و يرددها

$$
\text { و - الطلاب من بعده. }
$$

يرى مؤيد الطريقة الجمعية أن لكل طريقة مزاياها و عيوبها. و ما دام الأمر

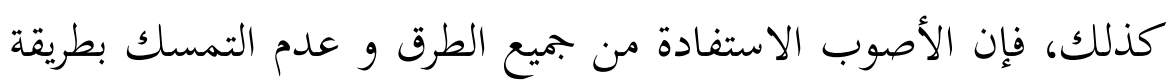
واحدة دون سواها. فكما ذكرنا سابقا إن للطريقة الحرفية مزلياها و عيوبها. و ينطبق الوضع ذاته على كل من الطريقة الصوتية و الطريقة المقطعية و طريقة الكلمة و طريقة الجملة.

\section{4- - - - الوسائل لتدريس مهارة القراءة}

هناك وسائل عديدة لتدريس مهارة القراءة في المدرسة الإبتدائية لتسهيل نقل

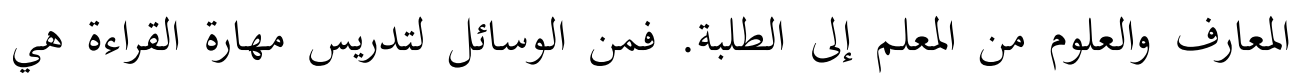

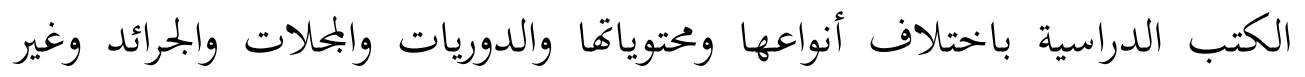
ذلك من أنواع المواد المقروءة.

والإستعانة بالبطاقات فكرة جديدة ترمى إلى تحبيب التلاميذ إلى القراءة، وإفادهم منها، وهي تتدرك على النحو الآتي، خاصة في التعليم الأساسي: بطاقات تنفيذ المعلومات: يتم إعداد بحموعة متدرجة من هذه البطاقات توزع على التلاميذ، ويراعى فيها كتابة بعض أوامر وطلبات بخط واضح، مثل: قف، إنه اجلس، افتح النافذة، اذهب إلى السبورة واكتب عليها: سنذهب غندا غندا في رحلة إلى كذا، والمطلوب من التلاميذ قراءقا في صمت وتنفيذ ما جاء فيها. 
بطاقات اختيار الإجابة الصحيحة: تعد بطاقات توزع على التلاميذ، وقد كتبت عليها قصص صغيرة، وفي ذيل كل قصة سؤال تحته عدة إجابات، من بينها الإجابة الصحيحة، والمطلوب من كل تلميذ أن يعين الإجابة الصحيحة في صمت، ويكتبها في كراسته مع رقم البطاقة، ثم يأحذ غيرها وهكذا. بطاقات الإجابة عن سؤال واحد: تعد بحموعة من البطاقات في كل منها قصة صغيرة، في فايتها سؤال، الإجابة عنه من صلب القصة، والمطلوب من كل تلميذ أن يقرأ بطاقته في صمت ويجيب عن السؤال في كراسته، مع تدوين رقم البطاقة.

بطاقات الألغاز: هي بجموعة من الألعاب، يتحدث في كل بطاقة منها إنسان أو

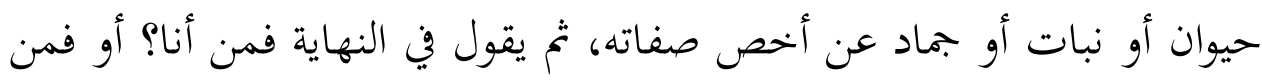
نحن؟ وعلى كل تلميذ أن يقرأ بطاقته صامتا، ثم يكتب الإجابة في كراسته.

بطاقات التكميل: الغرض منها إعداد بطاقات، تكتب في كل منها قصة ناقصة، قد نزعت منها بعض الكلمات، وتكتب هذه الكلمات في أعلى البطاقة أو في هايتها، وبعد أن يشرح المدرس الطريقة شفويا لتلاميذه يطالبهم بوضع الكلمات

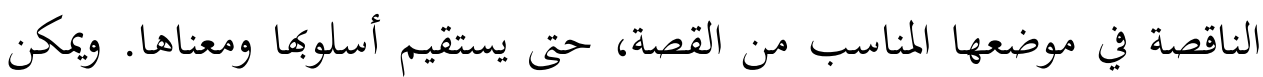

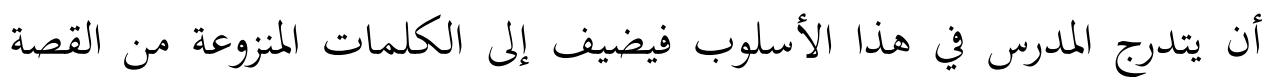

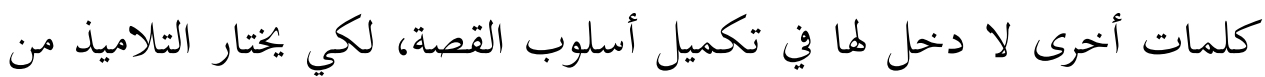
بينها ما يلائم الفراغ المتروك في القصة، ثم ينقل التلميذ القصة كاملة في كراسته، مع كتابة رقم البطاقة. ولهذا الأسلوب أثر في تنمية مواهب التلاميذ وتركيز

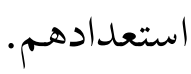

لعبة صناديق القصص: وتلخص فكرقا في كتابة قصص صغيرة على بطاقات من الورق المقوي بخط واضح، ثم تقسم البطاقات إلى أجزاء متناسبة في كل منها جزء 
من القصة، ثم توضع أجزاء كل قصة غير مرتبة في صندوق خاص بها، ثم توزغ

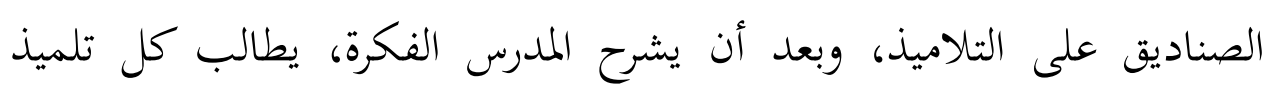

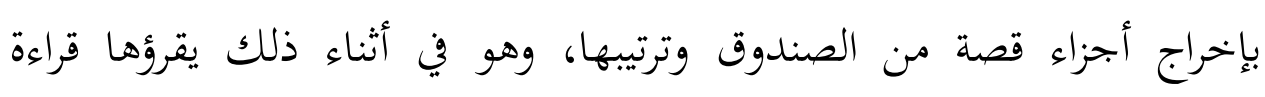

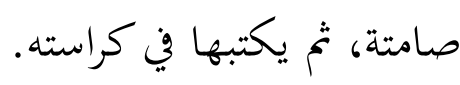

بطاقات الأسئلة الكثيرة: وتتناول قصصا وموضوعات قصيرة متدرجة، وفي غاية كل منها أسئلة كثيرة متعددة يجيب عنها التلميذ بعد قراءمّا صامتة.

وهذه البطاقات يمكن الانتفاع بما في السنوات المختلفة بالتعليم الأساسي بشرط

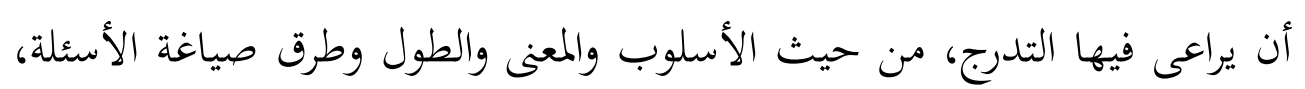
وهذا إلى جانب ما يقرؤه التلميذ في الكتب المقررة.

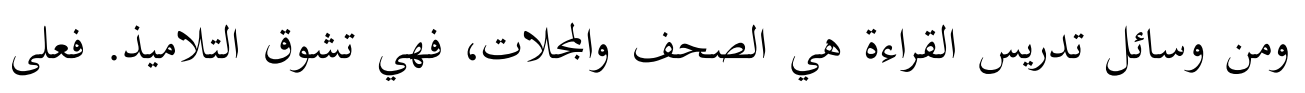

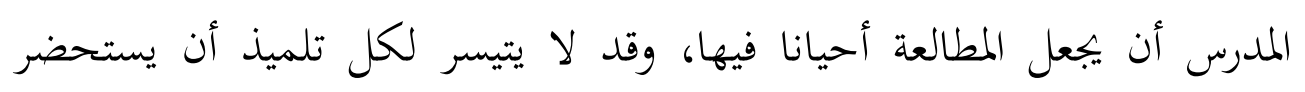

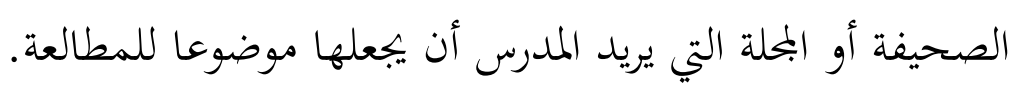

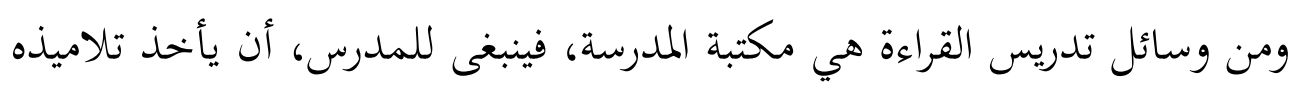

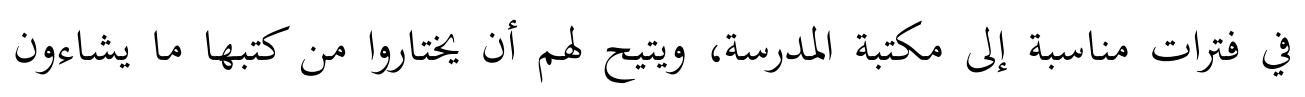

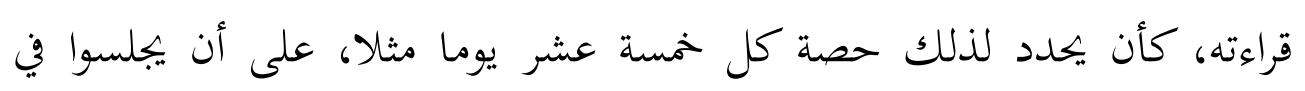

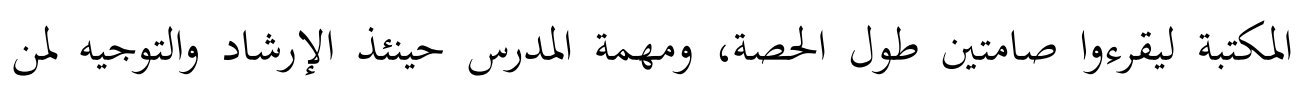
يكتاج إليهما، ومهمة التلميذ القراءة وتقييد ما يعن له.

\section{5- 5 الاختبارات لمهارة القراءة}

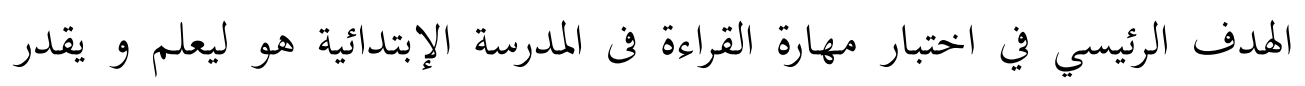

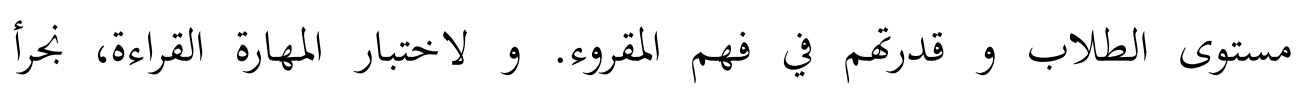
الاختبارات كما يلي:

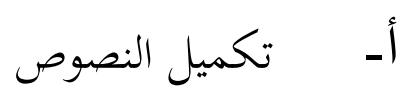


ب- - ب إجابة السؤال المتعلق بالنص

$$
\begin{aligned}
& \text { تـ- تلخيص النص } \\
& \text { ثـ- اختبار قراءة الجهرية } \\
& \text { ج- اختيار الأجوبة الموفورة }
\end{aligned}
$$

6- نماذج التقنيات والوسائل لتدريس مهارة القراءة في المستويات الدراسية

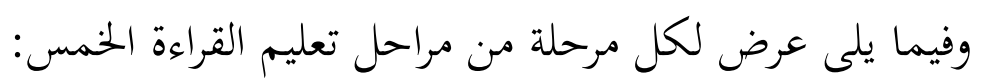

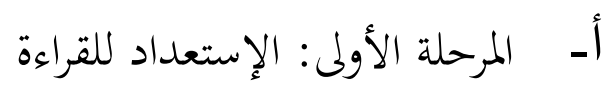

وتستغرق هذه المرحلة عادة سنوات ما قبل المدرسة والسنة الأولى الابتدائية، والهدف من هذه المرحلة هو توفير الخبرات والمرانة الكافية التي تنمي عند الأطفال الاستعداد للقراءة، واتخاذ التدابير اللازمة للتغلب على نواحى تهري النقص الجسمية والانفعالية التي تعوق التقدم في القراءة. ب- المرحلة الثانية: البدء في تعليم القراءة وتبدأ هذه المرحلة عادة عند التلاميذ الذين يكون نموهم عاديا في السنة الأولى الابتدائية. ويتم في هذه المرحلة تكوين العادات الأساسية في القراءة و بعض المهارات والقدرات. ج- المرحلة الثالثة: التوسع في القراءة وتسمى مرحلة التقدم السريع في اكتساب العادات الأساسية في القراءة. وتمتد هذه المرحلة من الصف الثان الابتدائي إلي الصف السادس الابتدائي (الثاني المتوسط بالكويت) وتمتاز هذه المرحلة بتنمية الشغف بالقراءة، ودقة الفهم لما يقرأ، والاستقلال في تعرف الكلمات، والانطلاق في القراءة الجهرية، وازدياد السرعة في القراءة، وقراءة القطع الأدبية السهلة، وقطع 
المعلومات والقصص، وبناء رصيد كبير من المفردات، وتنمية البحث عن مواد جديدة للقراءة.

دـ المرحلة الرابعة: توسيع الخبرات وزيادة القدرات والكفايات وتشتمل هذه المرحلة سنوات الدراسة الإعدادية وما يقابلها من سنوات المرحلة المتوسطة. وتتميز هذه المرحلة بالقراءة الواسعة التي تزيد خبرات القارئ غنى وامتدادا في ابتحاهات كثيرة. هـ المرحلة الخاسة: تمذيب العادات والأذواق والميول تشمل هذه المرحلة ما بقي من مراحل التعليم، فستستغرق الصفوف الثلاثة

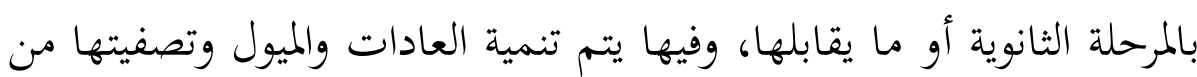

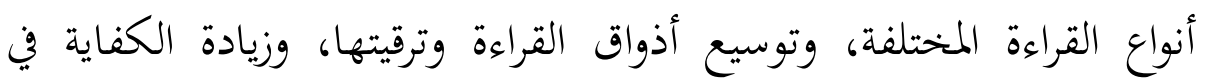

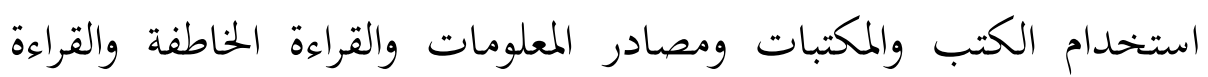
لاستمتاع والدرس.

\section{و- المصادر والمراجع المتعلقة بتدريس مهارة القراءة}

من أجل تطوير و ترقية مهارة القراءة عند الطلاب في المدرسة الإبتدائية، لا بد أن نبتدع التدريس بالطريقة المختلفة في كل المحاصرة. و من بعض الطريقة التي تستطيع أن تستخدم في تعليم القراءة هي باستعمال مختبرات اللغوية في تطبيق القراءة الجهرية و زيارة مكتبة المركزية في الجامعة و كذلك باستفادة المركز التعليم الذاتي. و في تطوير المواد الدراسية لتعليم القراءة، نستطيع أن نستفيد من المصادر المراجع كما يلي:

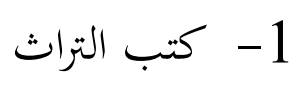

- كتب التفسير

- كتب سيياسية و إقتصادية و إجتماعية و غير ذلك من الكتب المتعلقة

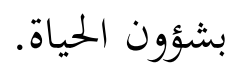




$$
\begin{aligned}
& \text { - كتب الفقه و أصوله } \\
& \text { - } \\
& \text { 2- البحلات العربية } \\
& \text { - المج - } \\
& \text { - - - الوعي - } \\
& \text { 3- الصحوف العربية } \\
& \text { - } \\
& \text { 4- الموقع الإنتيرنيت: }
\end{aligned}
$$

http://www.qassimedu.gov.sa/new/Trials/index1.htm www.gulfkids.com/ar/index.php?action=show res\&r id=79\&topic

$$
\text { id }=1334
$$

www.schoolarabia.net/asasia/duroos_1_2/arabi/sameer/sameer_ind

$$
\underline{\text { ex.htm }}
$$

vb.maharty.com/showthread.php?t=9736

cms.education.gov.il/EducationCMS/Units/Tochniyot_Limudim/Ar abicLashon/Kita1/LimudKriha.htm www.alrassedu.gov.sa/index/forum/showthread.php?t=6919 www.islamcvoice.com/vb/showthread.php?t=34833 foculty.ksu.edu.sa/aljarf/Grad\%20Students/

.pdföا www.goodreads.com/book/show/6224633. 


\section{المراجع}

اللغة العربية

أحمد فؤاد أفندي, طريقة تدريس اللغة العبية، مالانج: مشكات, 2006. د. محمد علي الخولي، أساليب تدريس اللغة العربية، الأردون: دار الفلاح للنشر و التوزيع، 2000 م.

د.حسن شحاتة، تعليم اللغة العربية بين النظرية والتطبيق، مصر: الدار المصرية اللبنانية، دون سنة.

صالح عبد المحيد, تعلم اللغات الحية بين النظرية و التطبيق, القاهرة: مكتبة لبنان, بدون سنة.

عبد العليم إبراهيم, الموجه الفني, لمدرسى اللغة العربية,مصر: 1119، الطبعة العاسرة.

علي أحمد مدكور, تدريس فنون اللغة العربية, القاهرة: دار الفكر العربي,202. محمد إبرهيم الخطيب, طرائق تعليم اللغة العربية, الرياض: 2003. محمد بن إبراهيم الخطيب، طرائق تعليم اللغة العربية، الرياض: مكتبة التوبة، 2003. محمود كامل الناقة, تعليم اللغة العربية للناطقين بلغات أخرى, السعودية: 1985. محمود كامل الناقةو رشدى أحمد طعيمة، طرائق تدريس اللغة العربية لغير الناطقين بها، إيسيسكون: منشورات المنظمة الإسلامية لتربية العلوم و الثقافة، 2003. - 2003.

اللغة الأجنابية

Drs. M. MaghfurWachid, MA, Agar Berbahasa Arab TerasaMudah, MetodeBaruMembaca-MemahamiTeks Arab, Bogor: IdeAPustakaUtama, 2003.

M. SoenardiDjiwandono, TesBahasadalamPengajaran, Bandung: Penerrbit ITB, 1996. 